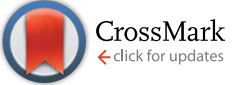

Cite this: RSC Adv., 2016, 6, 55884

\title{
Development of low cost mixed metal oxide based diesel oxidation catalysts and their comparative performance evaluation
}

\author{
Pravesh Chandra Shukla, ${ }^{a}$ Tarun Gupta, ${ }^{a}$ Nitin Kumar Labhsetwar ${ }^{b}$ \\ and Avinash Kumar Agarwal ${ }^{* c}$
}

\begin{abstract}
A four cylinder transportation diesel engine was used to evaluate the performance of two non-noble metal based diesel oxidation catalysts (DOC) with respect to various emission parameters such as particulate mass, elemental/organic carbon $(\mathrm{EC} / \mathrm{OC})$ content, and trace-metal content in particulates. Two new non-noble metal based DOCs were prepared and evaluated using mixed oxide $\left(\mathrm{CO}_{3} \mathrm{O}_{4}-\mathrm{CeO}_{2}\right)$ and perovskite catalysts with ceria support. Emissions were evaluated before and after the use of a commercial DOC for comparison. Experimental results showed that newly prepared DOCs were effective in reducing the organic carbon content of particulates. The effectiveness of these DOCs increased with higher engine loads. Performance of these two prepared DOCs was comparable to the commercial DOC. Trace metal concentration in particulates increased for most metals detected, primarily due to reduced organic carbon content of particulates emitted from the DOC. Prepared DOCs showed significant reduction in organic carbon at 50\% and higher engine loads. Significant organic carbon reduction was found to be responsible for particulate reduction.
\end{abstract}

Received 7th March 2016
Accepted 18th May 2016

DOI: $10.1039 / \mathrm{c} 6 \mathrm{ra0} 0621 \mathrm{~h}$

www.rsc.org/advances

adsorbers etc. DOC is an important after-treatment device for PM

\section{Introduction}

In last couple of decades, diesel engines have gained prominence in the medium-duty transportation sector compared to their gasoline counterparts, primarily due to their relatively higher efficiency and durability. Diesel engines emit relatively higher particulate matter $(\mathrm{PM})$ and oxides of nitrogen $\left(\mathrm{NO}_{x}\right) \cdot{ }^{1-5}$ Diesel particulate mainly comprise of elemental carbon (EC), organic carbon (OC), inorganic ions, and trace metals. ${ }^{6,7}$ Organic fraction of diesel particulate (sometimes referred as soluble organic fraction; SOF) is the main fraction responsible for its carcinogenic and mutagenic effects in humans. ${ }^{8-10}$ With increasingly stricter emission norms being adopted worldwide, it is becoming difficult to comply with $\mathrm{PM}$ and $\mathrm{NO}_{x}$ emission limits by using in-cylinder emission reduction techniques alone. Therefore, it has become a norm to use exhaust gas after-treatment devices, in addition to in-cylinder emission control techniques, so that engines/vehicles can comply with the emission norms. There are several aftertreatment devices used for the control of PM and $\mathrm{NO}_{x}$ emissions, such as diesel oxidation catalysts (DOC), diesel particulate filters (DPF), urea-selective catalytic reduction (Urea-SCR), $\mathrm{NO}_{x}$

${ }^{a}$ Department of Civil Engineering, Indian Institute of Technology Kanpur, Kanpur-208016, India

${ }^{b}$ National Environmental Engineering Research Institute, Council of Scientific \& Industrial Research, Nagpur, India

'Department of Mechanical Engineering, Indian Institute of Technology Kanpur, Kanpur-208016, India. E-mail: akag@iitk.ac.in reduction, which effectively reduces organic fraction of the particulate, however it does not reduce emission of elemental carbon (soot). It is a flow through device, which does not create any back-pressure on the engine, therefore it does not affect engine performance adversely. Primary role of DOC is to reduce soluble organic fraction (SOF) of the particulates however it also reduces carbon monoxide (CO) and hydrocarbon (HC) emissions effectively.

Most commercially available DOCs are coated with noble metals such as platinum (Pt), palladium (Pd) etc. which are very expensive rare earth metals. These issues encourage development of non-noble metal based catalysts for DOCs, which could prove to be a promising, long-term and sustainable solution for after-treatment devices. Few scientific studies ${ }^{11-22}$ investigated effectiveness of non-noble metal based catalysts for reduction of diesel emissions. Grisel and Nieuwenhuys, 2001 studied low temperature $\mathrm{CO}$ oxidation and methane $\left(\mathrm{CH}_{4}\right)$ oxidation over $\mathrm{Au} / \mathrm{Al}_{2} \mathrm{O}_{3}$ and $\mathrm{Au} / \mathrm{MO}_{x} / \mathrm{Al}_{2} \mathrm{O}_{3}(\mathrm{M}=\mathrm{Cr}, \mathrm{Mn}, \mathrm{Fe}, \mathrm{Co}, \mathrm{Ni}, \mathrm{Cu}, \mathrm{Zn})$ and concluded that addition of $\mathrm{MO}_{x}$ to $\mathrm{Au} / \mathrm{Al}_{2} \mathrm{O}_{3}$ stabilizes $\mathrm{Au}$ particles. ${ }^{5}$ Multi-component catalysts showed superior activity for low temperature $\mathrm{CO}$ oxidation compared to monocomponent catalysts. Au particle size was an important parameter affecting catalytic activity, however it was not dependent on the type of $\mathrm{MO}_{x}$. Oi-Uchisawa et al., 2001 reported that catalytic activity increased when $\mathrm{Pt} / \mathrm{MO}_{x}$ were supported on $\mathrm{SiC}$, where $\mathrm{MO}_{x}$ referred to $\mathrm{TiO}_{2}, \mathrm{ZrO}_{2}$ and $\mathrm{Al}_{2} \mathrm{O}_{3}$. The activity of $\mathrm{Pt} / \mathrm{TiO}_{2} / \mathrm{SiC}$ was highest amongst all tested catalysts for soot 
oxidation. ${ }^{23}$ Liang et al. investigated catalytic activity of $\mathrm{Cu} / \mathrm{Mn}$ doped ceria for diesel soot oxidation and reported that $\mathrm{Cu}-\mathrm{Ce}$ interaction significantly enhanced release of lattice oxygen from the oxides. Both catalysts showed superior catalytic behavior and selectivity to $\mathrm{CO}_{2}$ for soot oxidation, compared to ceria. ${ }^{24}$

India imports approximately $80 \%$ of its domestic petroleum requirements therefore country is looking for a sustainable alternative to imported mineral diesel. Biodiesel can be effectively used as partial or full replacement of mineral diesel. Biodiesel is a promising alternative fuel for partial replacement of mineral diesel, which results in significantly lower particulate emissions as well. Karanja and Jatropha are two biodiesel feedstocks available in south-east Asia in abundance. Experimental studies ${ }^{25,26}$ have shown that biodiesel emits lower PM emissions compared to baseline diesel due to its inherent oxygen content. Fuel-borne oxygen molecules help in achieving a higher degree of oxidation of hydrocarbons, which results in higher efficiency also. Its overall well-to-wheel $\mathrm{CO}_{2}$ emission is lower compared to mineral diesel. Biodiesel usage does not produce any net greenhouse gas because $\mathrm{CO}_{2}$ produced during combustion of biodiesel is equal to $\mathrm{CO}_{2}$ absorbed by plants during photosynthesis. ${ }^{25,27-29}$

In present study, an attempt has been made to prepare and evaluate two non-noble metal based DOCs for diesel engine emission reduction in combination with Karanja biodiesel blend (B20). These low cost, non-noble metal based DOCs can be used for stationary engine applications also. Combination of biodiesel blend can be effective in longer working life of these DOCs. Application of non-noble metal based catalysts for DOC can be a good option for particulate reduction from biodiesel fuelled engine and further reduce emissions. Co-Ce mixed oxide catalyst and lanthanum based perovskite catalysts were used for preparation of two new DOCs. Various emission parameters such as particulate mass reduction, trace metal emission, and EC/OC emission reductions were investigated in this experimental study and compared with a baseline commercial DOC.

\section{Experimental setup}

A four cylinder diesel engine (Tata Motors; Indica 475) was used for the experimental investigations of the DOCs. Fig. 1 shows the schematic of the experimental setup. The general specifications of the test engine are given in Table 1.

Test engine was coupled to an eddy current dynamometer and a dynamometer controller for applying load. Experiments were performed using diesel and Karanja biodiesel blend (20\% biodiesel (v/v) blend with diesel: B20) for various engine loads (no load, 25\%, 50\%, 75\% and full load) at rated engine speed (2500 rpm). Initially, engine was equipped with a commercial DOC (Engelhard) for baseline experiments. Emissions were recorded both upstream and downstream of commercial DOC. It was followed by experiments with two new non-noble metal based DOCs. Calorific value, viscosity and density of diesel and B20 were measured in the laboratory and are shown in Table 2.

A partial flow dilution tunnel (maintained at $52{ }^{\circ} \mathrm{C}$ ) was used to simulate the real world environment for collecting the particles from engine exhaust onto a pre-conditioned glass fiber

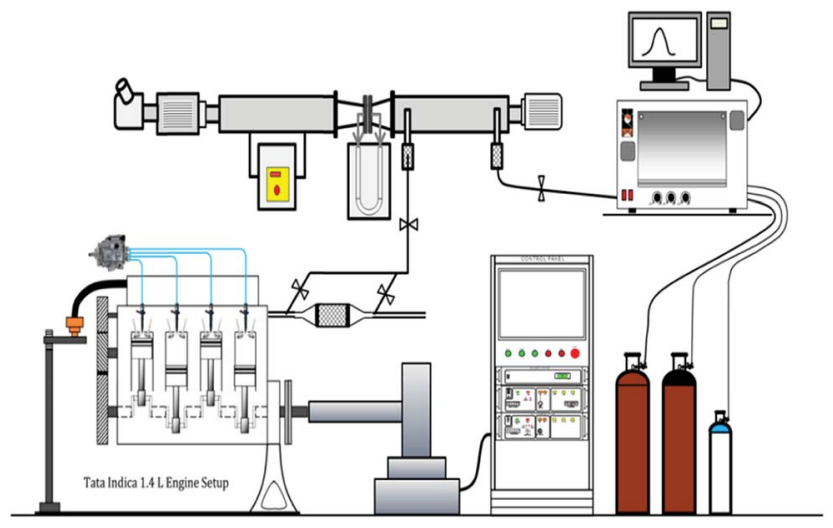

Fig. 1 Engine experimental setup.

Table 1 Technical specifications of the test engine
Make/model Engine type

No. of cylinders, configuration Bore/stroke Cubic capacity

Maximum power output

Maximum torque

Compression ratio

Fuel injection system
Tata Motors/Indica 475

Water cooled, IDI, diesel engine 4 , inline

$75 \mathrm{~mm} / 79.5 \mathrm{~mm}$

$1405 \mathrm{cc}$

39 kW@5000 rpm

85 Nm@2500 rpm

$22: 1$

Rotary pump with stop solenoid
Table 2 Important test fuel properties

\begin{tabular}{lcc}
\hline Property & Diesel & B20 \\
\hline Specific gravity & 0.846 & 0.848 \\
Kinematic viscosity $(\mathrm{cSt}) @ 30{ }^{\circ} \mathrm{C}$ & 2.60 & 3.39 \\
Calorific value $\left(\mathrm{MJ} \mathrm{kg}{ }^{-1}\right)$ & 42.21 & 38.28 \\
Flash point $\left({ }^{\circ} \mathrm{C}\right)$ & 52 & 79
\end{tabular}

filter paper (47 mm dia). A micro balance (Sartorius; CPA2P-F) was used to measure the filter weight and PM collected on filter paper. For trace metal analysis, Inductively Coupled Plasma-Optical Emission Spectroscopy (ICP-OES) was used. This is a type of emission spectroscopy which uses inductively coupled plasma to produce excited atoms and ions that emit electromagnetic radiations at wavelengths characteristic to a particular element. EC/OC analyzer (Sunset Laboratories, Semi-continuous EC/OC Field v.4) was used for EC/OC measurements. This instrument provides EC and OC values, which are comparable to National Institute for Occupational Safety and Health (NIOSH) recognized method 5040. All

Table 3 Specifications of ceramic substrates
Make

Material

Cell density

Shape

Diameter/length (mm)
Corning Inc., USA

Cordierite

$400 \mathrm{cpsi} / 6 \mathrm{mil}$

Cylindrical

143.8/127 
Table 4 Steps in coating of DOCs

Steps $\quad$ Method of preparation of DOCs

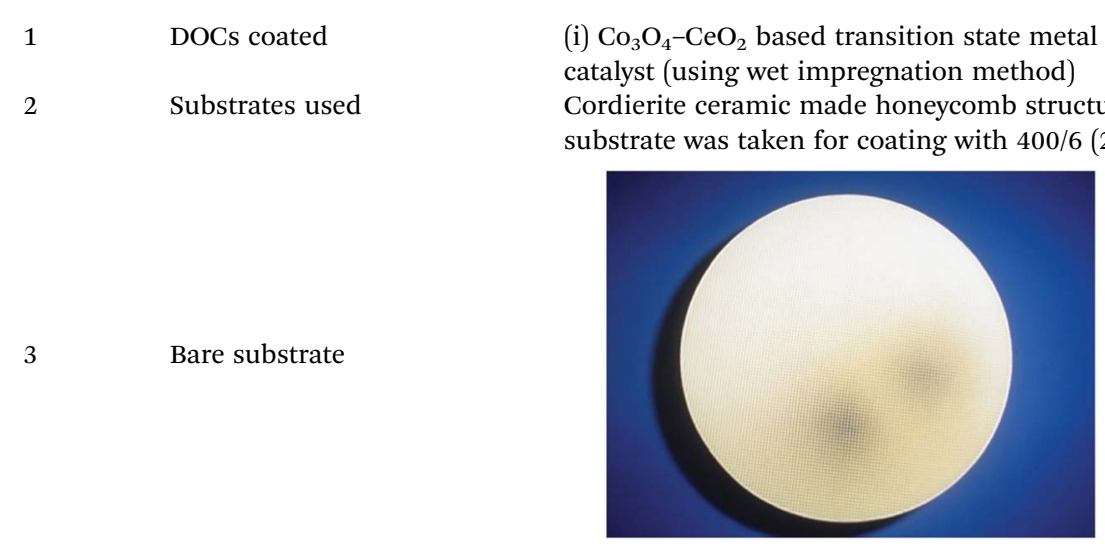
ceria $\left(\mathrm{CeO}_{2}\right)$

Catalyst material coating: $\mathrm{Co}_{3} \mathrm{O}_{4}-\mathrm{CeO}_{2}$ mixed oxide Promoter loading: Pd coating

Prepared DOC

DOC configurations

Fabrication of DOC canister

Engine testing
Oven dried at $150{ }^{\circ} \mathrm{C}$ for 6 hours

Cooled to ambient temperature

Calcination at $700{ }^{\circ} \mathrm{C}$ for 6 hours with slow ramping of temperature

Cooled to ambient temperature

Same procedure was followed as for step 4

Same procedure was followed as for step 4

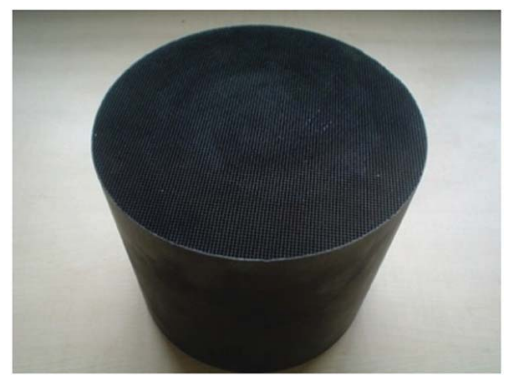

$\mathrm{CeO}_{2}$ support coating $=2 \%(\mathrm{w} / \mathrm{w})$ $\mathrm{Co}_{3} \mathrm{O}_{4}-\mathrm{CeO}_{2}$ mixed oxide catalysts coating $=3 \%(\mathrm{w} / \mathrm{w})$

Palladium promoter loading $=0.1 \%(\mathrm{w} / \mathrm{w})$ (ii) Lanthanum-manganese based perovskite catalyst (using wet impregnation method) Cordierite ceramic made honeycomb structure substrate was taken for coating with 400/6 (2l)

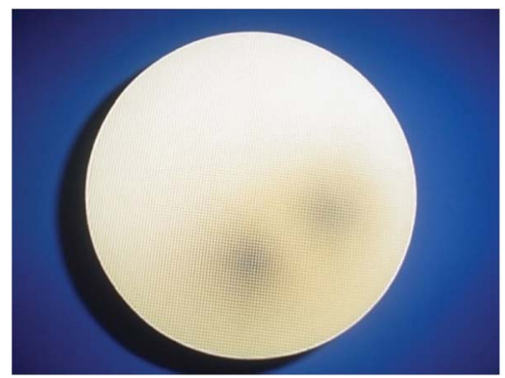

Oven dried at $150{ }^{\circ} \mathrm{C}$ for 6 hours

Cooled to ambient temperature

Calcination at $700{ }^{\circ} \mathrm{C}$ for 6 hours with slow ramping of temperature

Cooled to ambient temperature

Same procedure was followed as for step 4

Same procedure was followed as for step 4

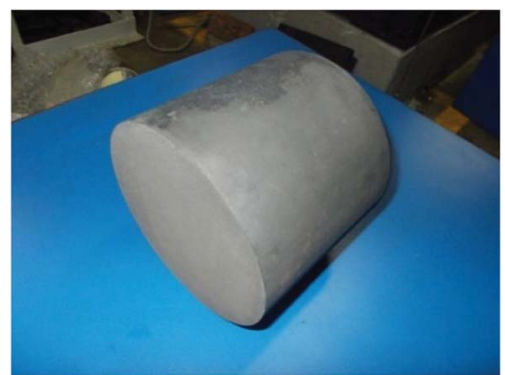

$\mathrm{CeO}_{2}$ support coating $=4.96 \%(\mathrm{w} / \mathrm{w})$

$\mathrm{LaMnO}_{3}$ catalyst coating $=4.99 \%(\mathrm{w} / \mathrm{w})$

Palladium promoter loading $=0.1 \%(\mathrm{w} / \mathrm{w})$
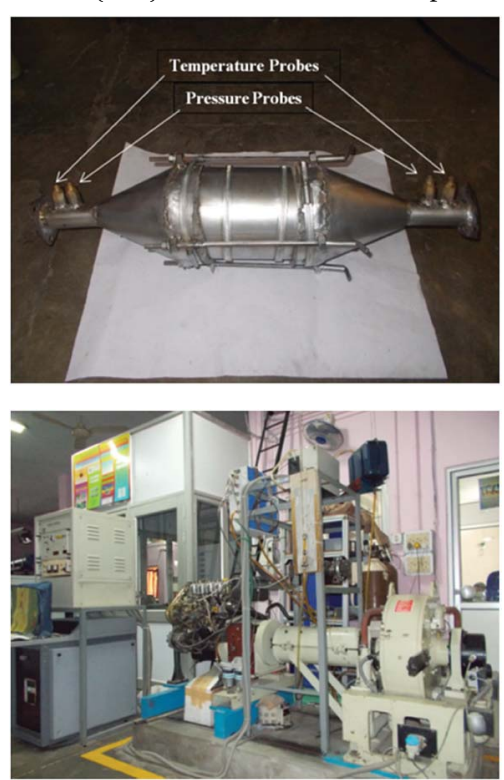
emission results reported in this study are average of at least three measurements.

\section{Preparation of DOCs}

Cylindrical substrates were chosen for this study because of their easier retrofitment in vehicle tail-pipe. Ceramic substrates were obtained from Corning Inc., USA. Detailed specifications of ceramic substrates are given in Table 3. Support and catalyst coating are important processes for preparing DOCs. Two DOCs were prepared using two different compositions of non-noble metal based catalysts.

In present study, two catalysts were used for the two DOCs; (i) $\mathrm{Co}_{3} \mathrm{O}_{4}-\mathrm{CeO}_{2}$ based transition state metal catalyst and (ii) lanthanum-manganese based perovskite catalyst $\left(\mathrm{LaMnO}_{3}\right)$. Wet impregnation method was used for catalyst coating. This is a common process normally used for catalyst coating onto the substrate. This process is usually adopted for practical and economic reasons, which allows coating of pre-shaped supports. ${ }^{30}$ Coating of $\mathrm{Co}_{3} \mathrm{O}_{4}-\mathrm{CeO}_{2}$ was based on previous literature, ${ }^{31}$ in which $\mathrm{Co}_{3} \mathrm{O}_{4}-\mathrm{CeO}_{2}$ mixed oxide catalysts having different compositions were tested for oxidation of gases like CO and evaluated using thermo-gravimetric analysis (TGA) method. This study was performed on small pieces of substrates in a bench test. It was found that $20: 80$ ratio of $\mathrm{Co}_{3} \mathrm{O}_{4}-\mathrm{CeO}_{2}$ (w/w) mixed oxide catalyst delivered the best oxidation performance amongst tested catalyst compositions. Therefore, $20: 80$ ratio of $\mathrm{Co}_{3} \mathrm{O}_{4}-\mathrm{CeO}_{2}(\mathrm{w} / \mathrm{w})$ mixed oxide catalyst was chosen in present study. For support loading, ceria $\left(\mathrm{CeO}_{2}\right)$ was chosen. The purpose of support material is to provide large surface area for adsorption and strong adhesion with catalyst. Larger the surface area of support loading, higher would be the contact between catalyst and pollutant species. Upon coating, ceria provides a surface area in the range of $55-85 \mathrm{~m}^{2} \mathrm{~g}^{-1} \cdot{ }^{32}$

Perovskite catalysts have a general formula of $\mathrm{ABO}_{3}$, where; ' $\mathrm{A}$ ' ions can be rare-earth alkaline metal, alkali and other large ions such as $\mathrm{Pb}^{2+}, \mathrm{Bi}^{3+}$ etc., and ' $\mathrm{B}$ ' can be transitional metal ions. ${ }^{33}$ They are cheaper compared to noble metal based catalysts and their peculiar chemical properties make them suitable for oxidation of soot and gaseous emissions. These transitional state ions show good redox properties. Apart from this, loosely bonded oxygen atoms and lattice defects provide good catalytic properties. $^{34}$ Lanthanum-manganese based perovskite catalyst $\left(\mathrm{LaMnO}_{3}\right)$ was used in DOCs in order to evaluate its performance under real engine operating conditions. Coating was performed in three layers; support coating, catalyst coating and promoter loading. A systematic approach for coating is shown in Table 4.

For simplicity of explanation, certain nomenclature is adopted for the DOCs used in this study. Table 5 lists the nomenclature used for different DOCs and raw exhaust.

\section{Results and discussion}

\section{Regulated gaseous emissions}

Fig. 2 shows regulated gaseous emissions with and without DOCs for diesel and B20 at $2500 \mathrm{rpm}$. Higher oxidation efficiencies of $\mathrm{DOC}_{1}, \mathrm{DOC}_{2}$ and $\mathrm{DOC}_{3}$ for $\mathrm{CO}$ can be observed for
Table 5 Nomenclature for commercial DOCs, prepared DOCs, and raw exhaust

Upstream

Upstream or without DOC

Commercial DOC

$\mathrm{DOC}_{1}$

$\mathrm{Co}_{3} \mathrm{O}_{4}-\mathrm{CeO}_{2}$ mixed oxide based DOC

$\mathrm{DOC}_{2}$

(1) $\mathrm{CeO}_{2}$ as support

(2) $\mathrm{Co}_{3} \mathrm{O}_{4}-\mathrm{CeO}_{2}$ mixed oxide catalyst

(3) Pd promoter

$\mathrm{LaMnO}_{3}$ perovskite based DOC

(1) $\mathrm{CeO}_{2}$ as support

(2) $\mathrm{LaMnO}_{3}$ perovskite catalyst

(3) Pd promoter

$\mathrm{DOC}_{3}$

both, diesel and B20. CO is mainly a product of incomplete combustion. Higher engine load leads to higher degree of incomplete combustion, which resulted in higher $\mathrm{CO}$ in raw exhaust. All DOCs were effective in CO oxidation at higher loads. As far as THC emissions are concerned (Fig. 2), DOC 1 delivered superior performance, followed by $\mathrm{DOC}_{3}$ and $\mathrm{DOC}_{2}$. The effectiveness of DOCs increased with increasing engine load (or alternatively with increasing in-cylinder temperature, resulting in higher exhaust gas temperature). Engine exhaust gas temperature played an important role in oxidation of hydrocarbons in presence of catalyst loaded on DOCs.

\section{Particulate mass (PM) emissions}

Fig. 3 shows PM emission upstream and downstream of $\mathrm{DOC}_{1}$, $\mathrm{DOC}_{2}$ and $\mathrm{DOC}_{3}$. As exhaust samples were collected after dilution in partial flow dilution tunnel, it is possible that there may be some inertial and thermophoretic losses in dilution tunnel. All three DOCs delivered good performance in PM reduction (Fig. 3). However, performance of $\mathrm{DOC}_{1}$ was superior compared to $\mathrm{DOC}_{2}$ and $\mathrm{DOC}_{3}$. Evaluation of $\mathrm{PM}$ reduction was also performed for B20 using prepared DOCs. $\mathrm{DOC}_{2}$ performance was slightly better compared to $\mathrm{DOC}_{3}$. It is easy to perceive from these results (Fig. 3) that oxidation of diesel particulates was more efficiently carried out by $\mathrm{Co}_{3} \mathrm{O}_{4}-\mathrm{CeO}_{2}$ based catalyst $\left(\mathrm{DOC}_{2}\right)$, while biodiesel particulates were more effectively oxidized by lanthanum based perovskite catalyst $\left(\mathrm{DOC}_{3}\right)$.

\section{Trace metal emissions}

Trace metals were unaffected by DOCs and trace metals were also present in the exhaust downstream of DOCs. Due to oxidation of OC fraction of particulates, relative percentage of trace metals increased in remaining particulate collected downstream of DOCs. Fig. 4 shows trace metal emissions in diesel and B20 exhaust, with and without DOCs. Trace metals concentration is represented in ' $\mathrm{mg} \mathrm{g}^{-1}$ of particulate' for comparison.

\section{Effect of fuels and operating conditions}

Biodiesel has several advantages over diesel such as no aromatics, presence of oxygen, very low sulfur content and low 


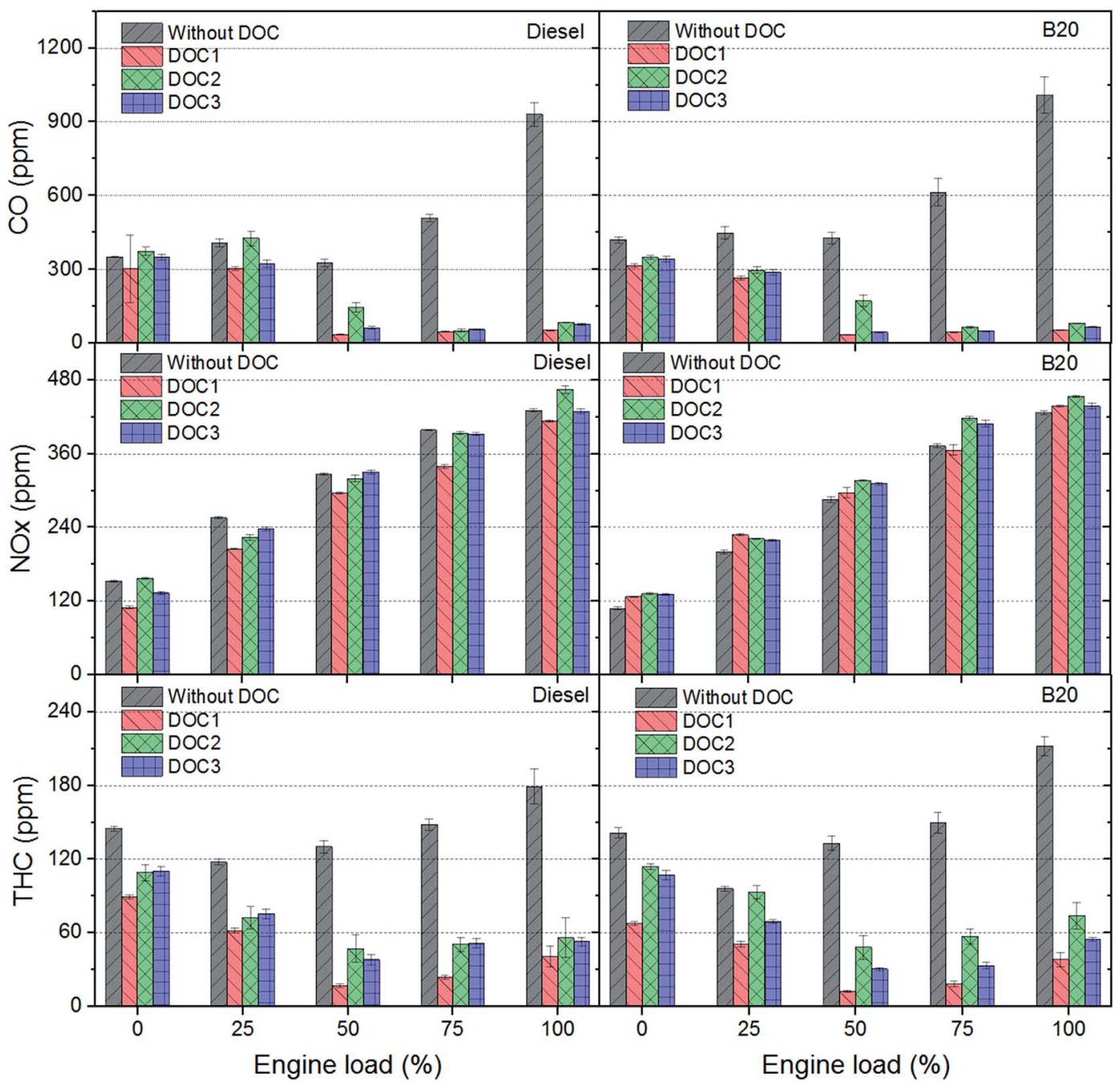

Fig. 2 Reduction in carbon monoxide (CO), oxides of nitrogen $\left(\mathrm{NO}_{x}\right)$ and total hydrocarbon (THC) emissions using DOCs.

trace metal content etc. ${ }^{35}$ Fig. 4 shows that most trace metals are in higher concentration at lower engine loads and concentration decreased with increasing engine loads, except for metals such as $\mathrm{Al}$ and $\mathrm{Ca}$. Trace metals such as $\mathrm{Al}, \mathrm{Ca}, \mathrm{Fe}, \mathrm{K}, \mathrm{Mg}$, $\mathrm{Na}$ and $\mathrm{Zn}$ were present in higher concentration per unit mass of particulate whereas trace metals such as $\mathrm{Ag}, \mathrm{Cd}, \mathrm{Co}, \mathrm{Cr}, \mathrm{Cu}, \mathrm{Mn}$ and $\mathrm{Ni}$ were present in relatively lower concentration per unit mass of particulate (Fig. 4). Blending of biodiesel with diesel did not show any significant change in trace metal content. This was attributed to presence of $80 \%$ diesel $(\mathrm{v} / \mathrm{v})$ in the blend, which significantly contributed towards trace metal emissions. Relatively higher viscosity and density of biodiesel resulted in generation of higher wear debris $\mathrm{s}^{36-39}$ and lubricating oil turned out to be the main source of trace metals in the engine exhaust. ${ }^{\mathbf{4 0 , 4 1}}$ Emission of trace metals was higher at lower engine loads and it decreased at higher engine loads for most metals. There are three main sources of trace metals in engine exhaust: (1) trace metals in fuel; (2) organo-metallic additives in lubricating oil; and (3) metallic wear debris from the engine components such as piston rings, piston, cylinder liner, valve seats, etc. ${ }^{42,43}$ Contribution of trace metals from these sources largely depends on engine operating conditions. Fuel-borne trace metal contribution always increased with increasing engine load, because of injection of higher fuel quantity in every cycle. Since engine speed essentially remained constant in trace metal study, trace metal contribution from lubricating oil and wear debris was not affected by engine speed but by engine load. Therefore particulate emissions increased due to higher fuel quantity injected per cycle, but trace metals didn't increase in the same proportion in the particulates.

\section{Effect of DOCs}

DOCs seemed to be ineffective in reducing emission of trace metals in particulates. It was observed that highest trace metal concentrations were observed for particulates collected after $\mathrm{DOC}_{1}$ from diesel, followed by significant trace metals concentration of particulates collected downstream of $\mathrm{DOC}_{2}$ and $\mathrm{DOC}_{3}$. No clear trends were evident.

Again, this indicated that $\mathrm{DOC}_{1}$ was most effective in the oxidation of organic fraction, resulting in higher concentration of trace metals in particulate. One important point to be noted 


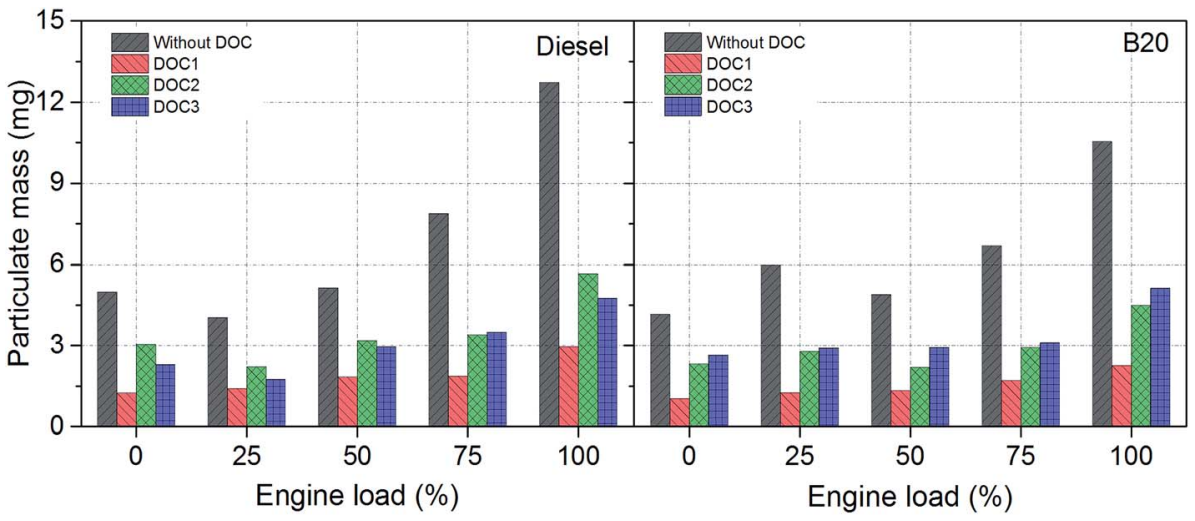

Fig. 3 Reduction in particulate mass emissions using DOCs.

is that there is no clear trend in emission of trace metals in this study. Trace metal emissions depend on several factors such as engine wear, combustion quality of fuel in combustion chamber, engine operating conditions etc.

\section{Elemental and organic carbon (EC/OC) emissions}

Fig. 5 shows EC/OC in engine exhaust particulates with and without DOCs for diesel and B20. EC and OC are the major

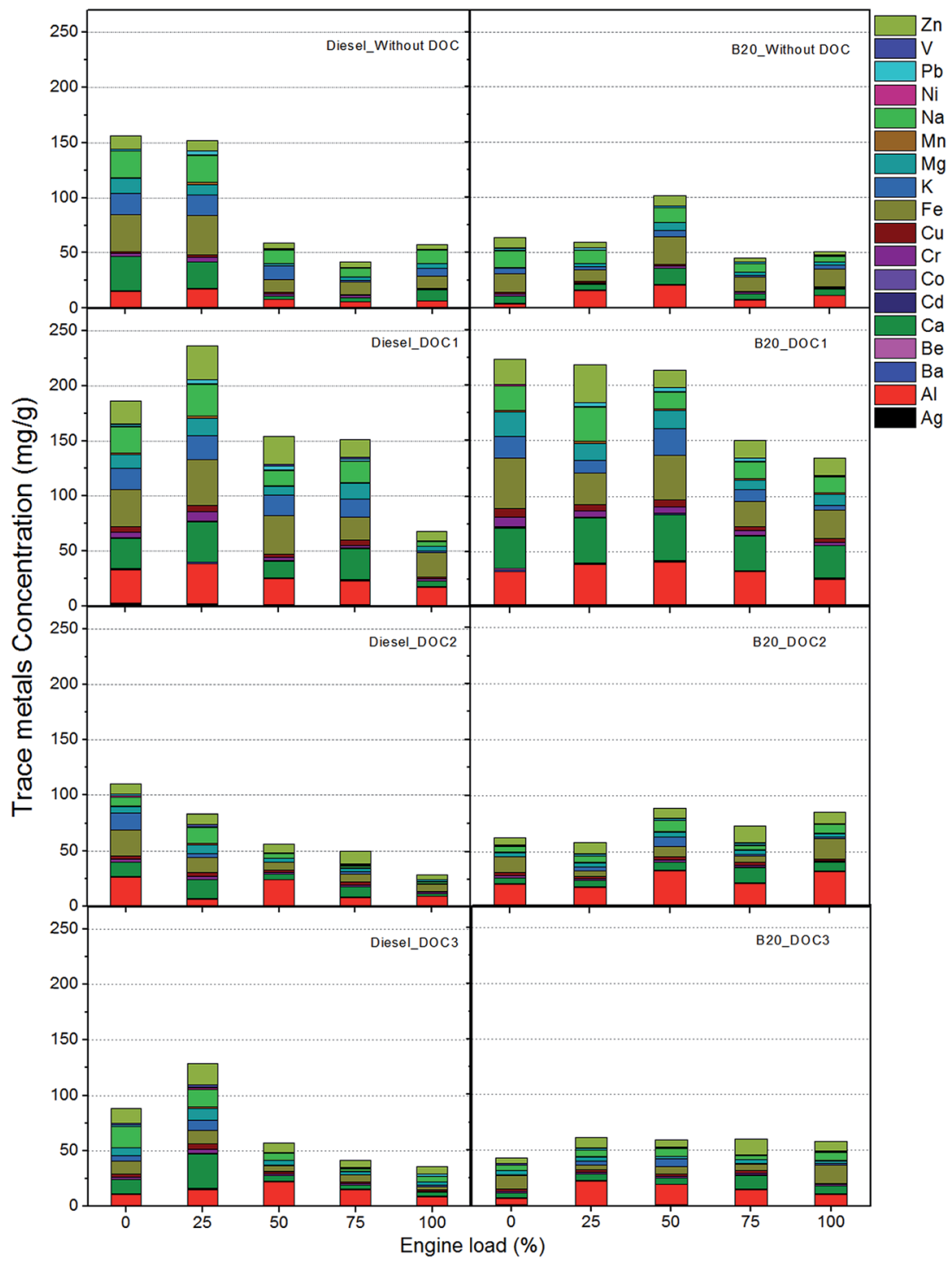

Fig. 4 Trace metal emissions with and without DOCs. 
constituents of particulate. Fractions of EC and OC in particulates mainly depend on engine operating conditions. OC of particulates is the fraction, which is considered to be responsible for hazardous health effects. ${ }^{25,44}$ In present study, EC/OC emissions were evaluated to determine; (1) effect of biodiesel; and (2) effect of DOCs.

\section{Effect of biodiesel}

Fig. 5 shows the EC emissions for diesel and B20. As engine load increased, EC also increased for both diesel and B20, however B20 showed significant reduction in EC in raw exhaust. For example, EC concentration reached approximately $1.2 \times 10^{5} \mu \mathrm{g}$ $\mathrm{m}^{-3}$ for diesel exhaust, while it was approximately $8 \times 10^{4} \mu \mathrm{g}$ $\mathrm{m}^{-3}$ for B20 exhaust. Clearly, biodiesel blending with diesel resulted in reduction of EC in particulates. Overall, there was no significant difference in OC emission, when engine was fuelled with either diesel or B20, except a slight reduction in case of B20. Significant reduction was observed in EC, when engine was fuelled with B20. This indicated that toxicity of particulates did not reduce significantly, although biodiesel reduced the carbon emissions. ${ }^{9}$ Since significant OC was still present in B20 exhaust, it showed potential to cause similar health and environmental effects as diesel exhaust. Agarwal et al., 2013 reported that OC emitted in the biodiesel exhaust is rather difficult to oxidize, compared to OC present in diesel exhaust.
Combined effect of EC and OC is represented by TC. Overall, TC showed a significant reduction for B20, mainly due to reduction in EC content of the particulate. ${ }^{9}$

\section{Effect of DOCs}

DOCs are known for their potential to oxidize OC fraction of particulates. Fig. 5 shows no significant EC reduction at low loads. However EC reduced at higher loads for both diesel and B20. EC is basically carbon and has an oxidation temperature of $\sim 600{ }^{\circ} \mathrm{C}$. It is difficult to oxidize EC at lower and intermediate engine loads because exhaust gas temperature (EGT) seldom reaches such a high value.

However, some localized high temperature regions, partial trapping of particulates in sampling line/dilution tunnel and thermophoretic losses may lead to slight reduction of EC content of exhaust sampled downstream of DOCs. As far as OC is concerned, almost no change was observed at lower loads and $25 \%$ load. Notably, most of OC fraction got oxidized at intermediate and higher engine loads when exhaust gas passed through DOCs. Slight differences were observed in TC reduction for tested DOCs. As soon as engine load increased to 50\%, EGT reached sufficient levels to activate DOC and in-turn oxidize OC fraction of particulate. Higher EGT led to superior performance of DOCs. Higher EGT leads to oxidation of organic compounds in presence of catalysts coated on DOCs. Catalysts need



Fig. 5 Elemental carbon (EC), organic carbon (OC) and total carbon (TC) in particulates with and without DOCs. 
a certain minimum temperature to attain their activation energy. Once they achieve the energy equivalent to activation energy, catalysts accelerate reaction kinetics for oxidation reactions of the harmful exhaust species.

The performance of $\mathrm{DOC}_{2}$ and $\mathrm{DOC}_{3}$ were comparable to $\mathrm{DOC}_{1}$ in oxidation of OC. Tested DOCs showed similar trend of OC reduction (slight increase in case of B20 at full load), although raw exhaust showed lower OC concentration in B20 exhaust compared to diesel exhaust. This indicated that composition of organic compounds present in B20 exhaust were difficult to oxidize compared to organic compounds present in diesel exhaust. Overall, DOCs were effective in removing most OC fraction of particulates at intermediate and higher engine loads.

As discussed, OC fraction of particulates is very important in terms of toxic effects on humans and the environment. It is important to understand the behavior of DOCs in oxidation of toxic compounds present in organic fraction of particulates. Fig. 6 shows relative fraction of EC and OC in exhaust particulates upstream and downstream of tested DOCs. OC fraction was higher in TC at lower engine loads. As engine load increased, fraction of OC decreased, with lowest fraction observed at full load. This was mainly due to higher oxidation of carbon at elevated combustion chamber temperature. OC fraction further decreased in PM samples collected downstream of DOCs. With the help of catalyst, DOCs oxidized most of OC fraction of particulates. For example, OC fraction was $\sim 34 \%$ (w/ $\mathrm{w})$ in diesel particulates, which reduced to $6 \%, 9 \%$ and $9 \%(\mathrm{w} /$ $\mathrm{w})$, when particulates were collected downstream of $\mathrm{DOC}_{1}$, $\mathrm{DOC}_{2}$ and $\mathrm{DOC}_{3}$ respectively. By closely observing percentage of OC fraction in TC for diesel and B20 particulates, an important inference can be drawn from Fig. 6. At full load, OC fraction was
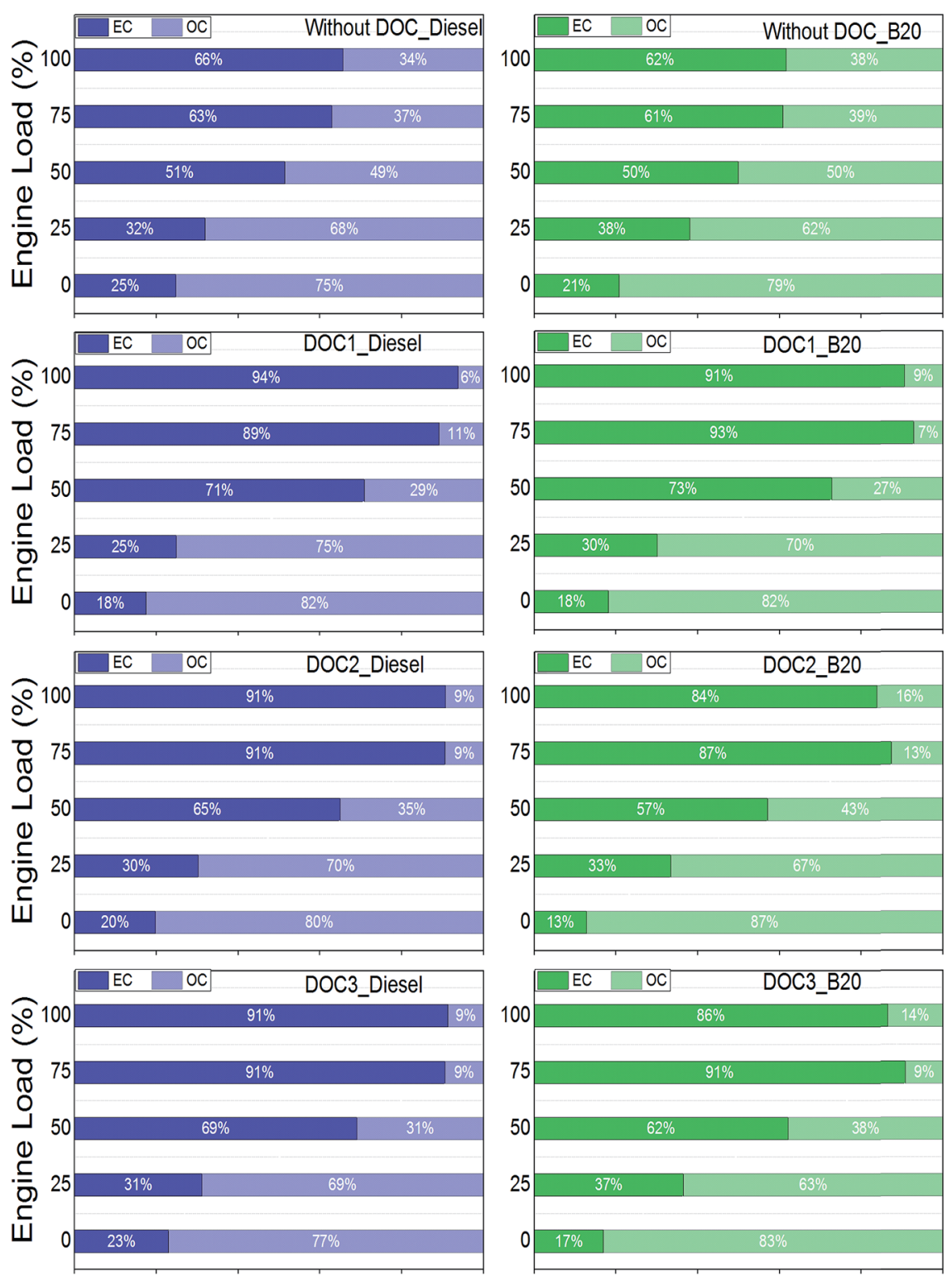

Fig. 6 Composition of elemental carbon (EC) and organic carbon (OC) in total carbon (TC) measured downstream of DOCs. 
$6 \%, 9 \%$ and $9 \%$ in particulates downstream of $\mathrm{DOC}_{1}, \mathrm{DOC}_{2}$ and $\mathrm{DOC}_{3}$ respectively for diesel, while it was $9 \%, 16 \%$ and $14 \%$ respectively for B20. Although OC concentration was lower for B20 exhaust compared to diesel exhaust (Fig. 5), higher OC fraction remained in TC (Fig. 6). This indicated that composition of OC fraction of B20 exhaust was relatively more difficult to oxidize compared to OC fraction of diesel exhaust.

\section{Conclusions}

Mineral diesel and Karanja biodiesel blend (B20) fuelled medium-duty transportation engine exhaust samples were analyzed for particulate mass, trace metals and EC/OC fractions. These parameters were analyzed for exhaust sampled upstream and downstream of a commercial DOC as well as two non-noble metal based DOCs prepared in-house. Commercial DOC ( DOC $_{1}$ ) showed slightly higher reduction in PM emissions, while prepared DOCs ( $\mathrm{DOC}_{2}$ and $\mathrm{DOC}_{3}$ ) showed comparable PM reduction. Perovskite catalyst based DOC $\left(\mathrm{DOC}_{3}\right)$ showed better $\mathrm{PM}$ reduction compared to $\mathrm{Co}_{3} \mathrm{O}_{4}-\mathrm{CeO}_{2}$ mixed oxide based DOC $\left(\mathrm{DOC}_{2}\right)$ for mineral diesel and vice versa for $\mathrm{B} 20$. Most trace metals were in high concentration at lower engine loads and decreased with increasing engine loads. B20 didn't demonstrate any significant change in trace metal emissions vis-à-vis mineral diesel. Exhaust samples downstream of DOCs showed relatively higher concentration of trace metals compared to raw exhaust. This was primarily due to the fact that DOCs significantly reduced OC fraction of particulates, leading to reduction in total PM mass, resulting in relatively higher trace metal concentration per unit mass of particulates. Tested DOCs showed higher reduction in OC at $50 \%$ and higher engine loads. Notably, reduction was observed in OC for B20 raw exhaust. However, it was comparable for particulates collected downstream of DOCs for both, diesel and B20. Percentage fraction of OC/EC clearly showed that OC contributed relatively higher fraction to TC than EC and vice versa at higher engine loads in raw exhaust.

In summary, the newly developed non-noble metal based DOCs were effective in emission reduction. Organic carbon emissions from engines were reduced drastically by these DOCs. Due to significantly lower cost, these catalysts are costeffective for their application in agricultural and on-road vehicles. This experimental study demonstrated application of low cost non-noble metal based DOCs for diesel emission reduction.

\section{Acknowledgements}

Authors would like to acknowledge the research grant from Science and Engineering Research Board (SERB), Department of Science and Technology (DST), Government of India (Grant No. SR/S3/MERC-0084/2011 dated 22 June 2012) for carrying out this study. Council of Scientific and Industrial Research (CSIR), Delhi supported Senior Research Associateship (Pool Scientist) to Mr Pravesh Chandra Shukla. Authors would also like to acknowledge Mr Roshan Lal and Yeshudas Jiotode of Engine Research Laboratory (ERL; http://www.iitk.ac.in/erl) for their valuable support during the experiments. Dr Neeraj Gupta helped significantly improve the manuscript.

\section{References}

$1 \mathrm{M}$. Dürnholz, G. Eifler and H. Endres, Exhaust-gas recirculation-A measure to reduce exhaust emissions of DI diesel engines, SAE Technical Paper, 1992.

2 K. Nakatani, S. Hirota, S. Takeshima, K. Itoh, T. Tanaka and K. Dohmae, Simultaneous PM and NOx reduction system for diesel engines, SAE Technical Paper, Report 0148-7191, 2002.

3 B. Van Setten, C. Van Gulijk, M. Makkee and J. Moulijn, Top. Catal., 2001, 16, 275-278.

4 N. Nejar, J. Garcia-Cortes, C. S.-M. de Lecea and M. IllánGómez, Catal. Commun., 2005, 6, 263-267.

5 R. Grisel and B. Nieuwenhuys, Catal. Today, 2001, 64, 69-81. 6 P. Eastwood, Particulate emissions from vehicles, John Wiley \& Sons, 2008.

7 D. B. Kittelson, J. Aerosol Sci., 1998, 29, 575-588.

8 M.-S. Bae, J. J. Schauer, J. T. DeMinter, J. R. Turner, D. Smith and R. A. Cary, Atmos. Environ., 2004, 38, 2885-2893.

9 A. K. Agarwal, T. Gupta, N. Dixit and P. C. Shukla, Inhalation Toxicol., 2013, 25, 325-332.

10 T. Gupta, N. Dixit, A. K. Agarwal and S. Gupta, The secondary organic carbon (SOC) formation from a CRDI automotive diesel engine exhaust, SAE Technical Paper, 2011.

11 D. Fino, N. Russo, G. Saracco and V. Specchia, J. Catal., 2003, 217, 367-375.

12 H. He, H. Dai and C. Au, Appl. Catal., B, 2001, 33, 65-80.

13 K.-S. Song, S.-K. Kang and S. D. Kim, Catal. Lett., 1997, 49, 65-68.

14 Y. Teraoka, K. Nakano, W. Shangguan and S. Kagawa, Catal. Today, 1996, 27, 107-113.

15 L. Li, X. Shen, P. Wang, X. Meng and F. Song, Appl. Surf. Sci., 2011, 257, 9519-9524.

16 W. Shangguan, Y. Teraoka and S. Kagawa, Appl. Catal., B, 1998, 16, 149-154.

17 V. Milt, C. Querini, E. Miró and M. Ulla, J. Catal., 2003, 220, 424-432.

18 P. Ciambelli, V. Palma, P. Russo and S. Vaccaro, J. Mol. Catal. A: Chem., 2003, 204, 673-681.

19 K. Masuda, K. Shinoda, T. Kato and K. Tsujimura, Appl. Catal., B, 1998, 15, 29-35.

20 S. Yuan, P. Mériaudeau and V. Perrichon, Appl. Catal., B, 1994, 3, 319-333.

21 I. Jarrige, K. Ishii, D. Matsumura, Y. Nishihata, M. Yoshida, H. Kishi, M. Taniguchi, M. Uenishi, H. Tanaka and H. Kasai, ACS Catal., 2015, 5, 1112-1118.

22 A. Eyssler, A. Winkler, O. Safonova, M. Nachtegaal, S. K. Matam, P. Hug, A. Weidenkaff and D. Ferri, Chem. Mater., 2012, 24, 1864-1875.

23 J. Oi-Uchisawa, A. Obuchi, R. Enomoto, J. Xu, T. Nanba, S. Liu and S. Kushiyama, Appl. Catal., B, 2001, 32, 257-268.

24 Q. Liang, X. Wu, D. Weng and H. Xu, Catal. Today, 2008, 139, 113-118.

25 A. K. Agarwal, T. Gupta, P. C. Shukla and A. Dhar, Energy Convers. Manage., 2015, 94, 311-330. 
26 S. Kaushik, M. Kumar, S. Thakur, M. Chhabra, K. Aggarwal and R. Tyagi, J. Chem. Pharm. Res., 2015, 7, 1075-1082.

27 A. K. Agarwal, Prog. Energy Combust. Sci., 2007, 33, 233-271.

28 S. Sinha, A. K. Agarwal and S. Garg, Energy Convers. Manage., 2008, 49, 1248-1257.

29 A. Murugesan, C. Umarani, R. Subramanian and N. Nedunchezhian, Renewable Sustainable Energy Rev., 2009, 13, 653-662.

30 G. Mul and J. A. Moulijn, Catal. Sci. Ser., 2005, 5, 1-32.

31 M. Dhakad, T. Mitshuhashi, S. Rayalu, P. Doggali, S. Bakardjiva, J. Subrt, D. Fino, H. Haneda and N. Labhsetwar, Catal. Today, 2008, 132, 188-193.

32 P. Periyat, F. Laffir, S. Tofail and E. Magner, RSC Adv., 2011, 1, 1794-1798.

33 L. G. Tejuca and J. Fierro, Properties and applications of perovskite-type oxides, CRC Press, 2000.

34 S. Ausadasuk, The Effect of Preparation on Catalytic Property of $\mathrm{LaCoO}_{3}$ and $\mathrm{LaMnO}_{3}$ Perovskite-Type Oxides, Kasetsart University, 2005.

35 H. Jung, D. B. Kittelson and M. R. Zachariah, Environ. Sci. Technol., 2006, 40, 4949-4955.
36 A. Agarwal, Proc. Inst. Mech. Eng., Part D, 2005, 219, 703-713. 37 S. Sinha and A. K. Agarwal, J. Eng. Gas Turbines Power, 2010, 132, 042801.

38 A. K. Agarwal and A. Dhar, J. Renewable Sustainable Energy, 2012, 4, 063138.

39 A. Dhar and A. K. Agarwal, Fuel, 2014, 134, 81-89.

40 M. J. Kleeman, S. G. Riddle, M. A. Robert and C. A. Jakober, Environ. Sci. Technol., 2007, 42, 235-242.

41 S. Brandenberger, M. Mohr, K. Grob and H. P. Neukom, Atmos. Environ., 2005, 39, 6985-6994.

42 M. Winther and E. Slentø, Heavy metal emissions for Danish road transport, National Environmental Research Institute, Aarhus University, 2010.

43 A. Ulrich, A. Wichser, A. Hess, N. Heeb, L. Emmenegger, J. Czerwinski, M. Kasper, J. Mooney and A. Mayer, 16th Conference on Combustion Generated Nanoparticles, Zurich, 2012, pp. 24-27.

44 P. C. Shukla, T. Gupta and A. K. Agarwal, Aerosol Air Qual. Res., 2014, 14, 934-942. 